\title{
Polymer Electrolytes Based on Borane/Poly(ethylene glycol) Methyl Ether for Lithium Batteries
}

\author{
Ali Murat Soydan ${ }^{1}$ and Recep Akdeniz ${ }^{2}$ \\ ${ }^{1}$ Institute of Energy Technologies, Gebze Technical University, Cayirova, Gebze, 41400 Kocaeli, Turkey \\ ${ }^{2}$ Department of Materials Science and Engineering, Gebze Technical University, Cayirova, Gebze, 41400 Kocaeli, Turkey \\ Correspondence should be addressed to Ali Murat Soydan; asoydan@gtu.edu.tr
}

Received 11 May 2017; Accepted 24 August 2017; Published 3 October 2017

Academic Editor: Ewa Schab-Balcerzak

Copyright ( 2017 Ali Murat Soydan and Recep Akdeniz. This is an open access article distributed under the Creative Commons Attribution License, which permits unrestricted use, distribution, and reproduction in any medium, provided the original work is properly cited.

\begin{abstract}
This work presents a different approach to preparing polymer electrolytes having borate ester groups for lithium ion batteries. The polymers were synthesized by reaction between poly(ethylene glycol) methyl ether (PEGME) and $\mathrm{BH}_{3}$-THF complex. Molecular weight of PEGMEs was changed with different chain lengths. Then the polymer electrolytes comprising boron were prepared by doping of the matrices with $\mathrm{CF}_{3} \mathrm{SO}_{3} \mathrm{Li}$ at various molar ratios with respect to EO to $\mathrm{Li}$ and they are abbreviated as PEGMEX$\mathrm{B}-Y$. The identification of the PEGME-borate esters was carried out by FTIR and ${ }^{1} \mathrm{H}$ NMR spectroscopy. Thermal properties of these electrolytes were investigated via thermogravimetric analysis (TGA) and differential scanning calorimetry (DSC). The ionic conductivity of these novel polymer electrolytes was studied by dielectric-impedance spectroscopy. Lithium ion conductivity of these electrolytes was changed by the length of PEGME as well as the doping ratios. They exhibit approximate conductivities of $10^{-4} \mathrm{~S} \cdot \mathrm{cm}^{-1}$ at $30^{\circ} \mathrm{C}$ and $10^{-3} \mathrm{~S} \cdot \mathrm{cm}^{-1}$ at $100^{\circ} \mathrm{C}$.
\end{abstract}

\section{Introduction}

Lithium ion batteries have been widely used as energy storage devices due to their high volumetric $\left(\mathrm{W} \mathrm{h} \mathrm{L}^{-1}\right)$ and gravimetric energy $\left(\mathrm{W} \mathrm{h} \mathrm{kg}^{-1}\right)$ density and high cycle life [1, 2], but their safety problems should be solved, especially for the high energy density applications such as portable phones and electric vehicles [1-3]. These drawbacks of lithium ion batteries are mainly caused by the use of organic liquid electrolytes due to high volatility, leakage, or flammability [4]. Solid polymer electrolyte seems to be an alternative to solve the safety problem, but the low ionic conductivity at room temperature is not enough to cover the required performance. The other alternative is aqueous electrolyte lithium ion batteries which promise higher safety due to nonflammability or toxicity of water $[5,6]$. Narrow electrochemical stability window of water $(1.23 \mathrm{~V})$ as a consequence of low energy density and instability of electrode materials prevents its applications. Although water in salt electrolyte system seems to be promising due to increased working voltage, this technology is still premature and the salts that are used are too expensive for any application $[7,8]$. Gel polymer electrolytes (GPEs) has higher ionic conductivity than solid polymer electrolyte, better stability than liquid electrolyte, and higher operating voltage than aqueous electrolytes yielding a different method to solve the problems of those energy storage systems [9-11].

Generally, GPE systems have been produced by immersing the polymer in a polar solvent where it dissolves the salt and enhances ionic conductivity. GPEs at lithium anode/electrolyte interface inhibit dendrite formation on lithium anode. Previously, GPEs based on poly(vinylidene fluoride) (PVdF) [12], poly(vinylidene fluoride cohexafluoropropylene) $\mathrm{P}$ (VdF-co-HFP) $[5,13]$, poly(methyl methacrylate) (PMMA) [14, 15], and poly(acrylonitrile) (PAN) [16] have been reported by several groups.

Another method of synthesis of GPEs was the direct production of PEG branched macromolecules that bear flexible side chains for ion transfer. For example, polymer boron containing branched chain systems were synthesized from boron trioxide, poly(ethylene glycol) (PEG), and methoxy end-capped PEG [17]. They have inserted a Lewis acid in 


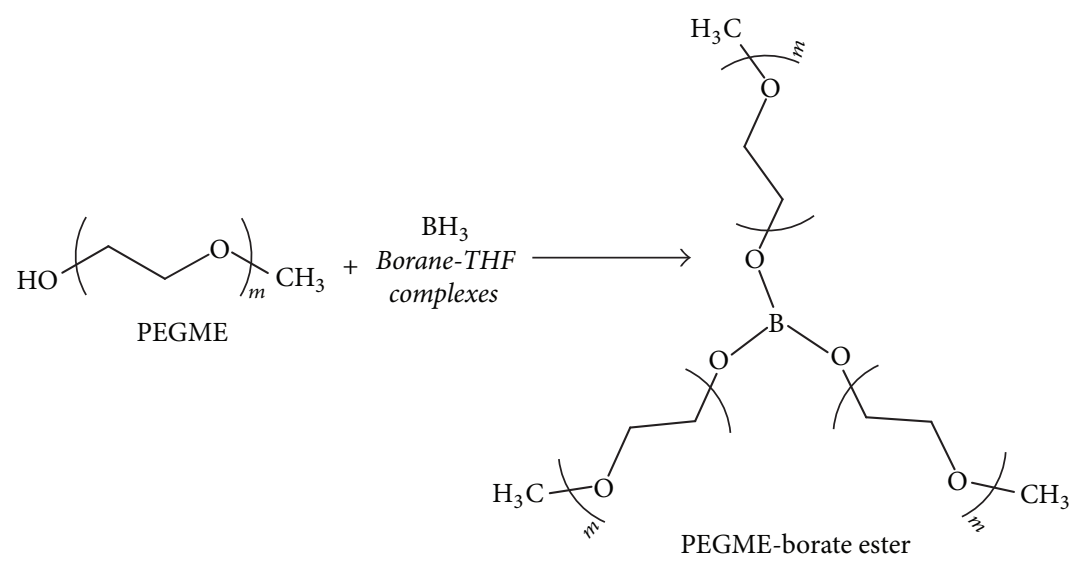

FIGURE 1: Synthesis scheme of PEGME-borate ester polymers.

the branched structure of a poly(ethylene oxide) (PEO) and then the transfer of species between the electrolyte and the electrode is improved as a result of ion-pairing in the electrolyte $[18,19]$. Lewis acid boron and Lewis-base oxygen interact with both cations and anions in the electrolytes and contribute to the ion-pairing in the electrolytes [2023]. Borane or borate derivatives can also improve the thermal stability of the electrolytes [24]. Lithium batteries or ultracapacitors include these kinds of stable branched electrolytes either directly or imbibing into porous nanofibers that have been produced via electrospinning.

In the present work, a more practical and innovative method was proposed for the synthesis of high ionic conductivity and stable boron containing PEG branched electrolytes for faster charge-discharging applications. Branched PEGborate esters were produced with different lengths. To have high ionic conductivity, the branched materials were doped with $\mathrm{CF}_{3} \mathrm{SO}_{3} \mathrm{Li}$ at several stoichiometric ratios. After drying the samples, they were characterized by Fourier transformed infrared (FTIR), differential scanning calorimetry (DSC), thermogravimetric analysis (TGA), and AC impedance spectroscopy.

\section{Experimental}

2.1. Materials. $\mathrm{BH}_{3} / \mathrm{THF}$ complex and PEGME (average $\mathrm{Mn}$ $=350,550$, and $750 \mathrm{~g} / \mathrm{mol}$ ) were purchased from Aldrich. Dimethylsulfoxide (DMSO, analytical reagent) was received from Merck. $\mathrm{CF}_{3} \mathrm{SO}_{3} \mathrm{Li} 97 \%$ was bought from Alfa Aesar and stored in a dry atmosphere.

2.2. Synthesis of the Graft Copolymer Electrolytes. The PEGborate esters were produced via the method as presented in Figure 1, by the reaction of poly(ethylene glycol) methyl ether, $\mathrm{CH}_{3} \mathrm{O}\left(\mathrm{CH}_{2} \mathrm{CH}_{2} \mathrm{O}\right)_{n} \mathrm{H}$, of various molecular weights $X=$ 350,550 , and $750 \mathrm{~g} / \mathrm{mol}$, and borane tetrahydrofuran complex solution, $\mathrm{BH}_{3} /$ THF. Firstly, PEGME was added to DMSO, and then $\mathrm{BH}_{3} / \mathrm{THF}$ was dropwise admixed into the solution. The resulting solution was stirred under $\mathrm{N}_{2}$ atmosphere and refluxed at $100^{\circ} \mathrm{C}$ for $24 \mathrm{~h}$. After that DMSO was removed by rotary evaporator at $80^{\circ} \mathrm{C}$, under vacuum. Finally, transparent pale yellowish liquid polymer (for $X=350 \mathrm{~g} / \mathrm{mol}$ ) and gels (for $X=550 \mathrm{~g} / \mathrm{mol}$ and $X=750 \mathrm{~g} / \mathrm{mol}$ ) were obtained. All the materials were kept in a Ar-filled glove box (moisture content below $1 \mathrm{ppm})$.

All the electrolytes were prepared by doping of branched polymers with lithium trifluoromethanesulfonate $\left(\mathrm{CF}_{3} \mathrm{SO}_{3} \mathrm{Li}, 97 \%\right)$ at several stoichiometric ratios. For example, the prepared PEGME-borate esters and lithium trifluoromethanesulfonate $\left(\mathrm{CF}_{3} \mathrm{SO}_{3} \mathrm{Li}, 97 \%\right)$ were transferred into a flask and stirred for about $4 \mathrm{~h}$. The concentration of $\mathrm{CF}_{3} \mathrm{SO}_{3} \mathrm{Li}$ was adjusted so that the molar ratio of lithium atoms to ether oxygen atoms in the PEGME-borate ester is $[\mathrm{EO}]:[\mathrm{Li}]=25,50,75$, and 100 . The final homogeneous viscous solutions were casted on Teflon plates.

2.3. Characterizations. A Bruker Alpha-P in ATR system was used to record the IR spectra within the range of $4000-400 \mathrm{~cm}^{-1}$ with a resolution $4 \mathrm{~cm}^{-1}$. Prior to Fourier transform infrared (FTIR) spectra measurements, materials were dried under vacuum and stored in a glove box.

Thermogravimetric analysis (TGA) polymer electrolytes were examined with a Perkin Elmer Pyris 1. The samples $(\sim 5 \mathrm{mg})$ were heated from $\mathrm{RT}$ to $750^{\circ} \mathrm{C}$ under inert atmosphere at a heating rate of $10^{\circ} \mathrm{C} \mathrm{min}{ }^{-1}$. Differential scanning calorimetry (DSC) (Perkin Elmer Pyris 1 instrument) was used to study glass transition temperature and melting temperatures. The temperature of the samples was reduced from RT to $-50^{\circ} \mathrm{C}$, kept isothermally for $10 \mathrm{~min}$, and then heated up to $150^{\circ} \mathrm{C}$. Then the samples were cooled to $-50^{\circ} \mathrm{C}$ and reheated to $180^{\circ} \mathrm{C}$. All thermograms were recorded at a rate of $10^{\circ} \mathrm{C}$ under inert gas flow. All DSC experiments were done in duplicate and the thermograms shown refer to the final heating.

Novocontrol dielectric-impedance analyzer was used to study alternating current (AC) conductivities of the samples in the frequency range from $0.1 \mathrm{~Hz}$ to $3 \mathrm{MHz}$ with respect to temperature. The samples were poured into the specially designed vacuum sealed liquid cell with parallel plate electrodes with a diameter of $20 \mathrm{~mm}$ and a thickness of approximately $4.5 \mathrm{~mm}$ and their conductivities were measured under an inert atmosphere. 


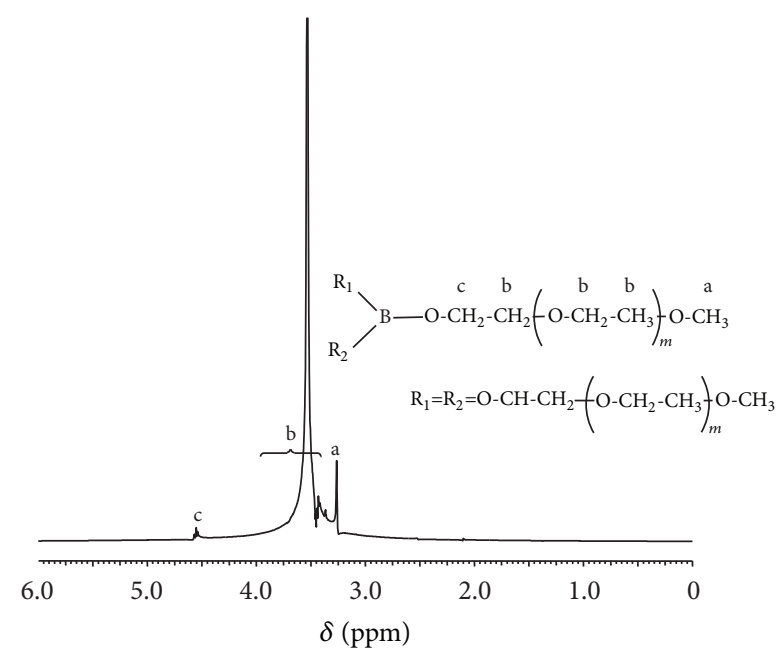

Figure 2: ${ }^{1} \mathrm{H}$ NMR spectra of PEGME coordinated boron.

\section{Result and Discussion}

3.1. NMR Study. The ${ }^{1} \mathrm{H}$ NMR spectrum of the final boron comprising branched polymer, PEGME550-B, is presented in Figure 2. The chemical shift at $3.26 \mathrm{ppm}$ (a) clearly indicates the methoxy group at terminal position. The prominent peak at 3.42 and $3.53 \mathrm{ppm}$ (b) can be attributed to ethylene oxide in the polymer backbone: esteric methyl groups, which were shifted to the downfield at $4.55 \mathrm{ppm}$ (c) due to deshielding effect, which is a result of interactions between the boron and the ethylene oxide units.

3.2. FTIR Study. The FTIR spectrum of the branched polymer electrolyte PEGME350-B- $Y$ is given in Figure 3. All the samples show a peak located at $3400 \mathrm{~cm}^{-1}$ which corresponds to the absorption of hydroxyl units. It is clearly shown that disappearance of this peak illustrates highest transformation of the hydroxyl groups into borate esters [21]. In addition, strong bands at $2910-2870 \mathrm{~cm}^{-1}$ due to $\mathrm{C}-\mathrm{H}$ stretching of the polymer electrolytes and weaker peaks located around $667 \mathrm{~cm}^{-1}$ belong to B-O units $[25,26]$. The peaks at $\sim 1029$ and 1350 were characteristic band of B-O-C bond and also antisymmetric stretching vibration of $\mathrm{B}-\mathrm{O}$ [17]. This confirms the reaction of $\mathrm{BH}_{3}$ with hydroxyl units of PEGs. The broadening of the C-O-C peaks near $1150 \mathrm{~cm}^{-1}$, especially at higher doping ratios, indicates a higher degree of interactions between $\mathrm{Li}^{+}$and EO [27]. The characteristic absorptions of the pure $\mathrm{LiCF}_{3} \mathrm{SO}_{3}$ are located at 1266 and $1033 \mathrm{~cm}^{-1}$, corresponding to asymmetric $\mathrm{SO}_{3}$ and symmetric $\mathrm{SO}_{3}$ vibrations of $\mathrm{LiCF}_{3} \mathrm{SO}_{3}$, respectively [28]. Consequently, the FTIR spectra reveal that borate ester polymer electrolytes were successfully synthesized.

3.3. Thermal Properties. The thermal stability of polymer electrolytes is a critical issue for application in rechargeable lithium polymer batteries. The thermal stabilities of these novel electrolytes were studied by TGA at various Li-salt.

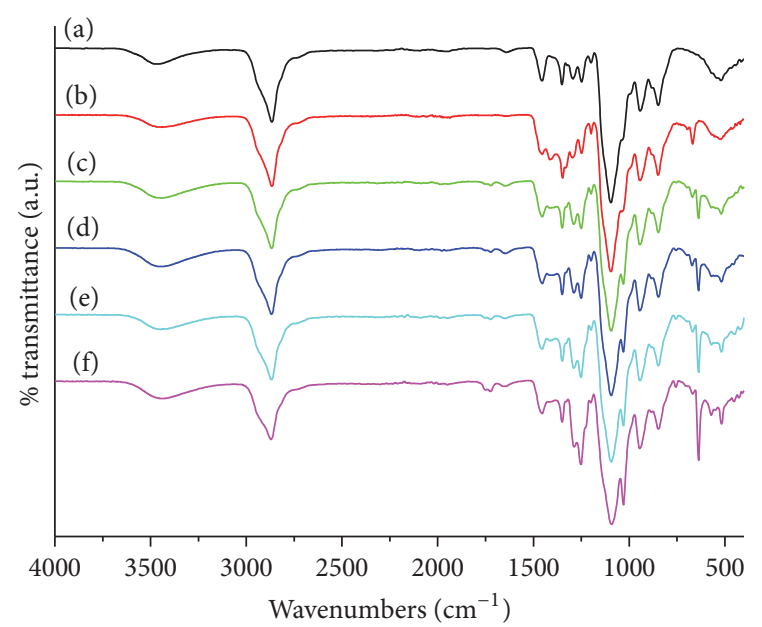

FIgURE 3: Comparison of FTIR spectra of PEGME350 (a); PEGME350-B (b); and PEGME350-B- $Y,(Y=100$ (c), 75 (d), 50 (e), and 25 (f)).

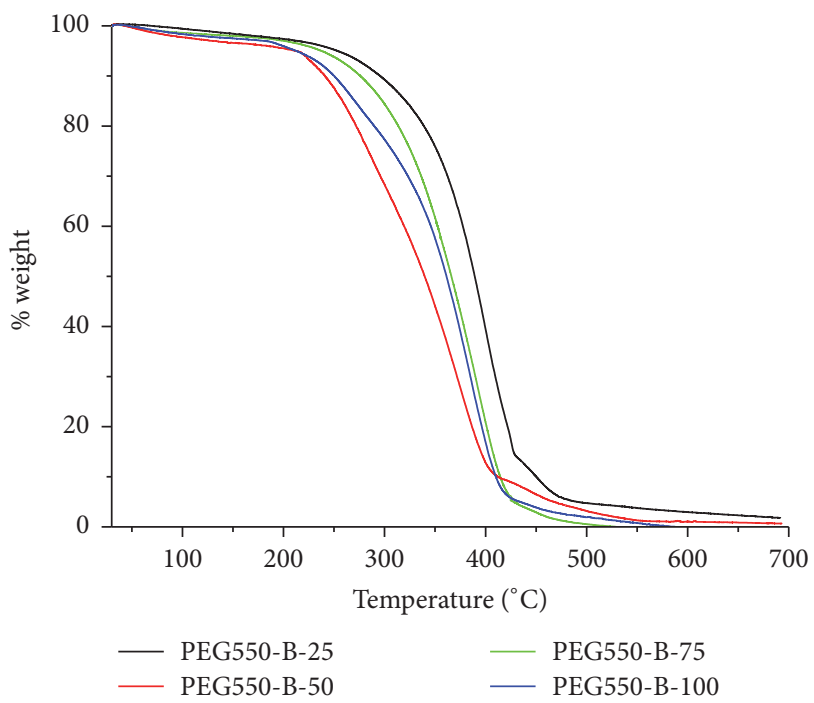

FIgURE 4: Thermogravimetric analysis of PEGME550-B- $Y(Y=25$, 50,75 , and 100) polymer electrolytes under nitrogen atmosphere at a heating rate of $10^{\circ} \mathrm{C} \cdot \mathrm{min}^{-1}$.

Figure 4 shows the TGA results of the polymer electrolytes PEGME550-B-Y. As seen in the figure, the onset of degradation temperature of $\mathrm{LiCF}_{3} \mathrm{SO}_{3}$ introduced PEGMEborate esters is approximately $180^{\circ} \mathrm{C}$ and degradation occurs via two steps. It was previously mentioned that this behavior may be due to the weakness of the $\mathrm{C}-\mathrm{O}$ bond caused by a reduction in electronic density by $\mathrm{Li} / \mathrm{EO}[29,30]$. All the samples can be said to be thermally stable up to $180^{\circ} \mathrm{C}$ which is far higher than the operating temperature of lithium ion batteries.

DSC was used to investigate the thermal transitions of the polymer electrolytes with various $\mathrm{Li}$-salt contents. Figure 5 shows the melting endotherms of polymer electrolyte systems. Clearly, for all samples, there is no definite $T_{g}$ within the given temperature range. The polymer electrolytes of 


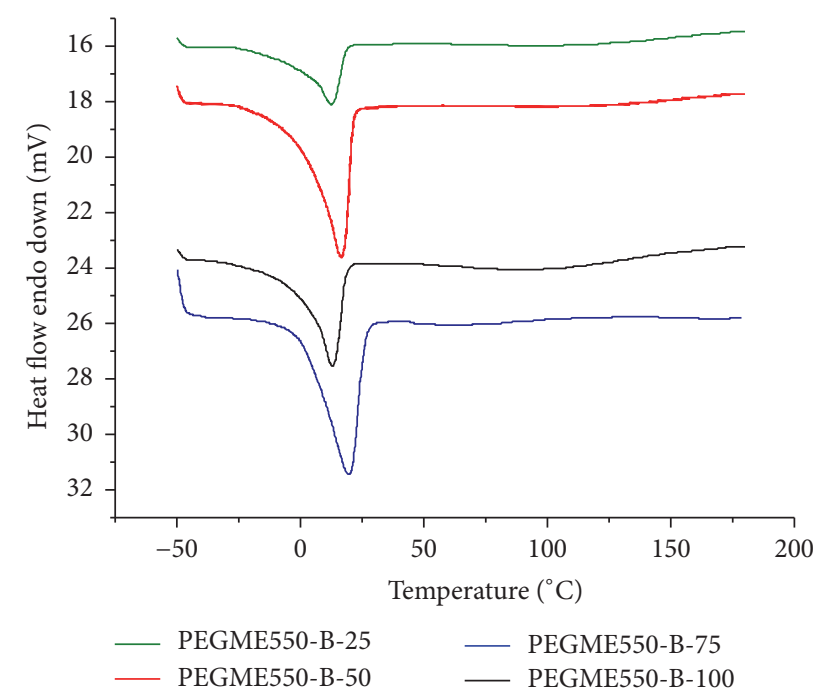

Figure 5: DSC curves of PEGME550-B- $Y(Y=25,50,75$, and 100) polymer electrolytes. Second heating run endotherms are presented at a heating rate of $10^{\circ} \mathrm{C} / \mathrm{min}$.

PEGME550-B- $Y(Y=25,50,75$, and 100) showed respective melting endotherms at $13.50,16.40,13.15$, and $19.80^{\circ} \mathrm{C}$.

3.4. Ionic Conductivity. Frequency dependence of the ac conductivity $\left(\sigma_{\mathrm{ac}}\right)$ of PEGME350 B- 25 within $20-100^{\circ} \mathrm{C}$ is given in Figure 7. It can be observed that the ac conductivity versus frequency for various temperatures exhibits almost linear increasing at low frequencies which are assigned to the polarization of the electrodes; then frequency independent plateau regions which belong to $\sigma_{\mathrm{dc}}$ are well developed at higher frequencies $(F>100 \mathrm{~Hz})$.

The $\sigma_{\mathrm{dc}}$ versus inverse temperature variations of the polymer electrolytes with different molecular weight of PEGME and doping ratios of $\mathrm{LiCF}_{3} \mathrm{SO}_{3}$ are shown in Figure 6. The bend in the curve has been observed in ion conducting polymer electrolytes and has been explained by the free volume concept $[30,31]$, which can be described by the Vogel-Tamman-Fulcher (VTF) equation (1). To have better insight into the temperature dependence of $\sigma_{\mathrm{dc}}$, the conductivity data have been fitted to the equation.

$$
\log \sigma=\log \sigma_{0}-\frac{E v}{\left[k\left(T-T_{0}\right)\right]},
$$

where $\sigma_{0}(\mathrm{~S} / \mathrm{cm})$ is the conductivity at infinite temperature, $E v$ is the Vogel activation energy $(\mathrm{eV}), k$ is the Boltzmann constant, $T$ is the absolute temperature, and $T_{0}$ is the Vogel temperature which is the onset of polymer segmental relaxations $\left({ }^{\circ} \mathrm{C}\right)$.

Figure 7 shows the temperature dependence of ionic conductivity for the polymer electrolytes. The ionic conductivity increases with decreasing molecular weight of the starting PEGME.

Over the whole temperature range, the sample containing PEGME-borate ester whose molecular weight is $X=350$ shows the highest ionic conductivity, and the values of the

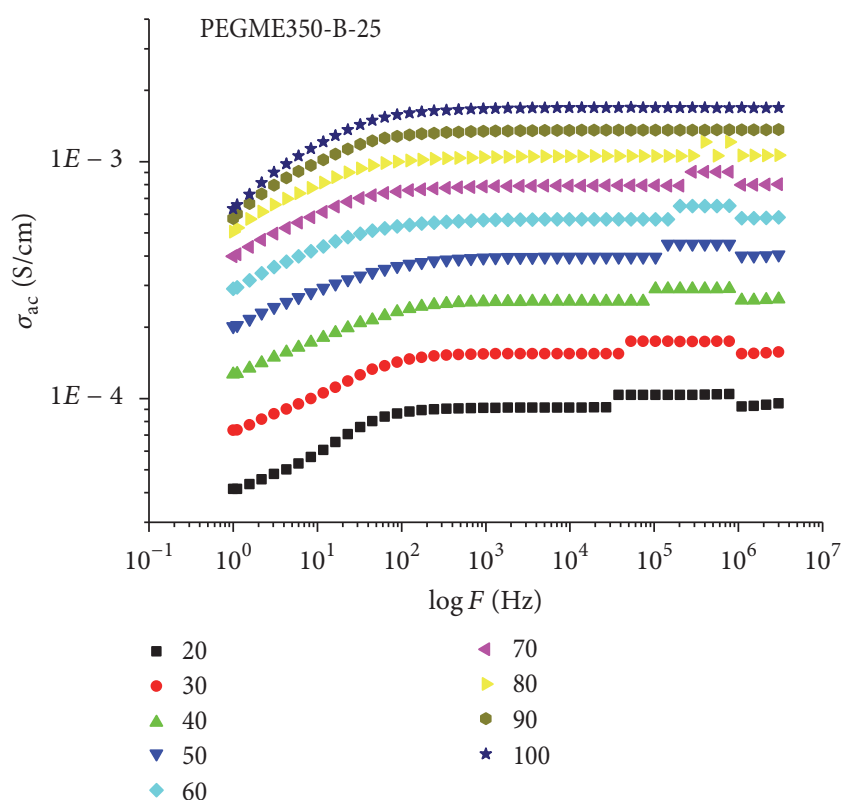

FIGURE 6: The ac conductivity versus frequency of anhydrous PEG ME350-B-25 borate ester polymer electrolyte at various temperatures.

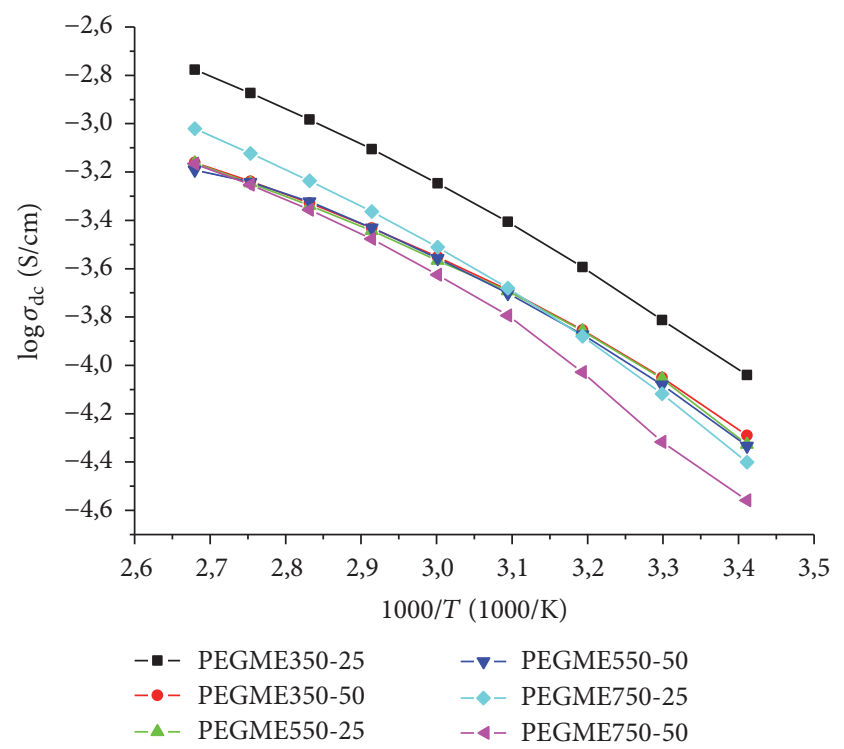

FIgURE 7: Temperature dependence of the DC conductivities of PEGMEX-B-Y polymer electrolytes.

ionic conductivity were $1.5 \times 10^{-4} \mathrm{~S} \mathrm{~cm}^{-1}$ at $30^{\circ} \mathrm{C}$ and $1.7 \times$ $10^{-3} \mathrm{~S} \cdot \mathrm{cm}^{-1}$ at $100^{\circ} \mathrm{C}$. It is thought that the PEG-borate ester $(X=350)$ has the highest ability to dissolve and transfer $\mathrm{Li}$ ions which may be due to the shorter EO chain length. At higher chain lengths, it is clearly seen that there is almost no significant increase of the conductivity. In particular, PEGME 750-25 seems to be of optimum composition and shows slightly higher conductivity at higher temperatures. 


\section{Conclusions}

This study presents a new approach to preparing polymer electrolytes having borate ester groups for lithium ion batteries. The PEGME-borate esters were synthesized by the reaction of poly(ethylene glycol) methyl ether and borane tetrahydrofuran complex solution, $\mathrm{BH}_{3} / \mathrm{THF}$. Then the electrolytes were successfully produced by doping of the polymer matrix with $\mathrm{CF}_{3} \mathrm{SO}_{3} \mathrm{Li}$ at different ratios which are abbreviated as PEGMEX-B-Y. NMR, FTIR, TGA, and dielectric-impedance spectroscopy methods were used for the characterization of these electrolytes. The FTIR and NMR spectra reveal that borate ester polymer electrolytes were successfully synthesized. TGA demonstrated that the samples are thermally stable up to $200^{\circ} \mathrm{C}$. The conductivity results illustrated that the lithium ion conductivity of branched polymer electrolytes depends on chain length of PEGME as well as the $\mathrm{CF}_{3} \mathrm{SO}_{3} \mathrm{Li}$ content. The polymer electrolyte PEGME350-B-25 yielded a promising ionic conductivity of $1.5 \times 10^{-4} \mathrm{~S} \mathrm{~cm}^{-1}$ at $30^{\circ} \mathrm{C}$ and $1.7 \times 10^{-3} \mathrm{~S} \cdot \mathrm{cm}^{-1}$ at $100^{\circ} \mathrm{C}$. The curved lines at conductivity versus $1000 / \mathrm{T}$, especially at higher salt content, are typical for VTF behavior, indicating a positive contribution of segmental relaxation to the ion motion. These materials are nonvolatile, have promising ionic conductivity, and can be suggested for use in energy storage systems.

\section{Conflicts of Interest}

The authors declare that there are no conflicts of interest regarding the publication of this paper.

\section{References}

[1] M. Armand and J.-M. Tarascon, "Building better batteries," Nature, vol. 451, no. 7179, pp. 652-657, 2008.

[2] J.-M. Tarascon and M. Armand, "Issues and challenges facing rechargeable lithium batteries," Nature, vol. 414, no. 6861, pp. 359-367, 2001.

[3] P. Huang, C. Lethien, S. Pinaud et al., "On-chip and freestanding elastic carbon films for micro-supercapacitors," Science, vol. 351, no. 6274 , pp. 691-695, 2016.

[4] G. Nagasubramanian and K. Fenton, "Reducing Li-ion safety hazards through use of non-flammable solvents and recent work at Sandia National Laboratories," Electrochimica Acta, vol. 101, pp. 3-10, 2013

[5] W. Tang, Y. Zhu, Y. Hou et al., "Aqueous rechargeable lithium batteries as an energy storage system of superfast charging," Energy \& Environmental Science, vol. 6, pp. 2093-2104, 2013.

[6] H. Kim, J. Hong, K.-Y. Park, H. Kim, S.-W. Kim, and K. Kang, "Aqueous rechargeable Li and Na ion batteries," Chemical Reviews, vol. 114, no. 23, pp. 11788-11827, 2014.

[7] L. Suo, O. Borodin, T. Gao et al., "'Water-in-salt' electrolyte enables high-voltage aqueous lithium-ion chemistries," Science, vol. 350, no. 6263, pp. 938-943, 2015.

[8] R.-S. Kühnel, D. Reber, and C. Battaglia, "A high-voltage aqueous electrolyte for sodium-ion batteries," ACS Energy Letters, vol. 2, no. 9, pp. 2005-2006, 2017.

[9] P. C. Barbosa, L. C. Rodrigues, M. M. Silva et al., "Solid-state electrochromic devices using pTMC/PEO blends as polymer electrolytes," Electrochimica Acta, vol. 55, no. 4, pp. 1495-1502, 2010.

[10] H. Gao, Q. Tian, and K. Lian, "Polyvinyl alcohol-heteropoly acid polymer electrolytes and their applications in electrochemical capacitors," Solid State Ionics, vol. 181, no. 19-20, pp. 874-876, 2010.

[11] D. K. Pradhan, R. N. P. Choudhary, and B. K. Samantaray, "Studies of dielectric and electrical properties of plasticized polymer nanocomposite electrolytes," Materials Chemistry and Physics, vol. 115, no. 2-3, pp. 557-561, 2009.

[12] J. R. Kim, S. W. Choi, S. M. Jo, W. S. Lee, and B. C. Kim, "Electrospun PVdF-based fibrous polymer electrolytes for lithium ion polymer batteries," Electrochimica Acta, vol. 50, no. 1, pp. 69-75, 2004.

[13] X. Li, G. Cheruvally, J.-K. Kim et al., "Polymer electrolytes based on an electrospun poly(vinylidene fluoride-co-hexafluoropropylene) membrane for lithium batteries," Journal of Power Sources, vol. 167, no. 2, pp. 491-498, 2007.

[14] O. Bohnke, G. Frand, M. Rezrazi, C. Rousselot, and C. Truche, "Fast ion transport in new lithium electrolytes gelled with PMMA. 1. Influence of polymer concentration," Solid State Ionics, vol. 66, no. 1-2, pp. 97-104, 1993.

[15] O. Bohnke, G. Frand, M. Rezrazi, C. Rousselot, and C. Truche, "Fast ion transport in new lithium electrolytes gelled with PMMA. 2. Influence of lithium salt concentration," Solid State Ionics, vol. 66, no. 1-2, pp. 105-112, 1993.

[16] D. Peramunage, D. M. Pasquariello, and K. M. Abraham, "Polyacrylonitrile-Based Electrolytes with Ternary Solvent Mixtures as Plasticizers," Journal of the Electrochemical Society, vol. 142, no. 6, pp. 1789-1798, 1995.

[17] P.-Y. Pennarun, P. Jannasch, S. Papaefthimiou, N. Skarpentzos, and P. Yianoulis, "High coloration performance of electrochromic devices assembled with electrolytes based on a branched boronate ester polymer and lithium perchlorate salt," Thin Solid Films, vol. 514, no. 1-2, pp. 258-266, 2006.

[18] F. Zhou, D. R. MacFarlane, and M. Forsyth, "Boroxine ring compounds as dissociation enhancers in gel polyelectrolytes," Electrochimica Acta, vol. 48, no. 12, pp. 1749-1758, 2003.

[19] B. S. Lalia, N. Yoshimoto, M. Egashira, and M. Morita, "Effects of Lewis-acid polymer on the electrochemical properties of alkylphosphate-based non-flammable gel electrolyte," Journal of Power Sources, vol. 194, no. 1, pp. 531-535, 2009.

[20] N.-S. Choi, S.-W. Ryu, and J.-K. Park, "Effect of tris(methoxy diethylene glycol) borate on ionic conductivity and electrochemical stability of ethylene carbonate-based electrolyte," Electrochimica Acta, vol. 53, no. 22, pp. 6575-6579, 2008.

[21] P.-Y. Pennarun and P. Jannasch, "Electrolytes based on $\mathrm{LiClO}_{4}$ and branched PEG-boronate ester polymers for electrochromics," Solid State Ionics, vol. 176, no. 11-12, pp. 1103-1112, 2005.

[22] J. McBreen, H. S. Lee, X. Q. Yang, and X. Sun, "New approaches to the design of polymer and liquid electrolytes for lithium batteries," Journal of Power Sources, vol. 89, no. 2, pp. 163-167, 2000.

[23] E. Zygadło-Monikowska, Z. Florjańczyk, A. Tomaszewska et al., "New boron compounds as additives for lithium polymer electrolytes," Electrochimica Acta, vol. 53, no. 4, pp. 1481-1489, 2007.

[24] Y. Kato, K. Hasumi, S. Yokoyama et al., "Polymer electrolyte plasticized with PEG-borate ester having high ionic conductivity and thermal stability," Solid State Ionics, vol. 150, no. 3-4, pp. 355-361, 2002. 
[25] P. Chetri, N. N. Dass, and N. S. Sarma, "Conductivity measurement of poly(vinyl borate) and its lithium derivative in solid state," Materials Science and Engineering B: Solid-State Materials for Advanced Technology, vol. 139, no. 2-3, pp. 261-264, 2007.

[26] M. Şenel, A. Bozkurt, and A. Baykal, "An investigation of the proton conductivities of hydrated poly(vinyl alcohol)/boric acid complex electrolytes," Ionics, vol. 13, no. 4, pp. 263-266, 2007.

[27] P.-Y. Pennarun and P. Jannasch, "Influence of the alkali metal salt on the properties of solid electrolytes derived from a Lewis acidic polyether," Solid State Ionics, vol. 176, no. 23-24, pp. 18491859, 2005.

[28] H. Aydin and A. Bozkurt, "Synthesis, characterization, and ionic conductivity of novel crosslinked polymer electrolytes for Liion batteries," Journal of Applied Polymer Science, vol. 124, no. 2, pp. 1193-1199, 2012.

[29] Y.-H. Liang, C.-C. Wang, and C.-Y. Chen, "Synthesis and characterization of a new network polymer electrolyte containing polyether in the main chains and side chains," European Polymer Journal, vol. 44, no. 7, pp. 2376-2384, 2008.

[30] M. H. Cohen and D. Turnbull, "Molecular transport in liquids and glasses," The Journal of Chemical Physics, vol. 31, no. 5, pp. 1164-1169, 1959.

[31] G. S. Grest and M. H. Cohen, "Liquid-glass transition: dependence of the glass transition on heating and cooling rates," Physical Review B, vol. 21, no. 9, pp. 4113-4117, 1980. 

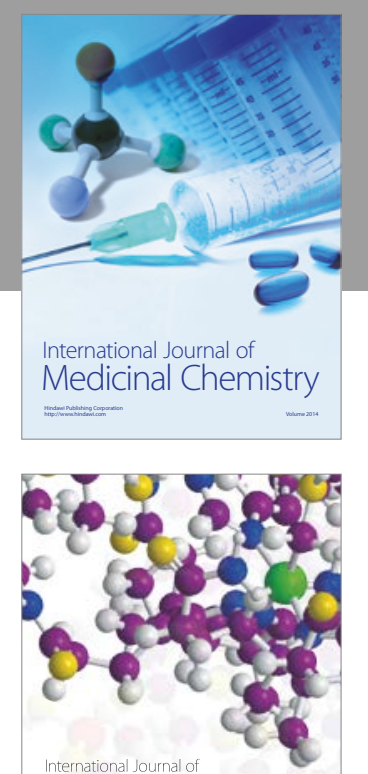

Carbohydrate Chemistry

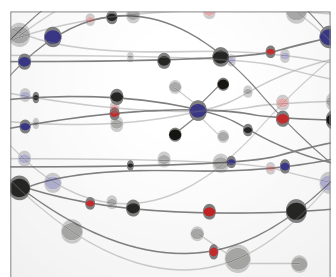

The Scientific World Journal
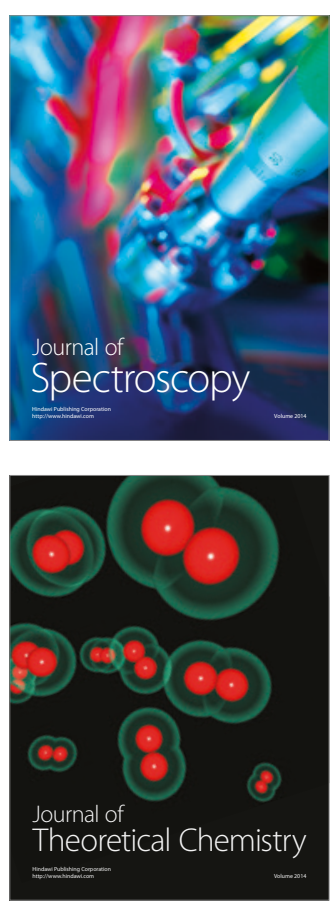
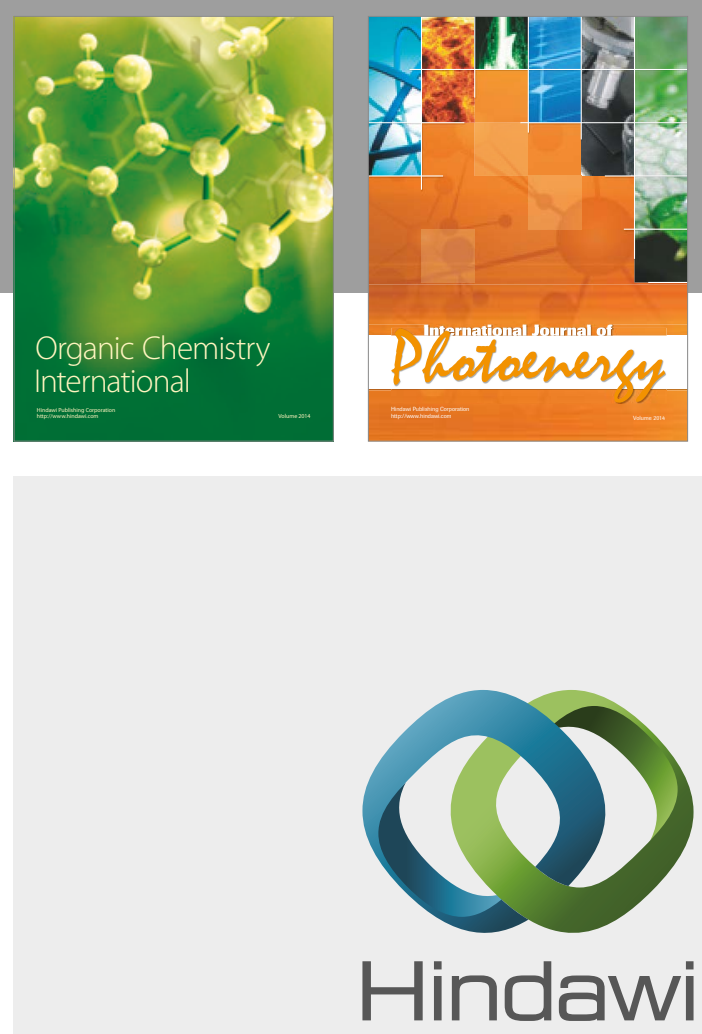

Submit your manuscripts at

https://www.hindawi.com

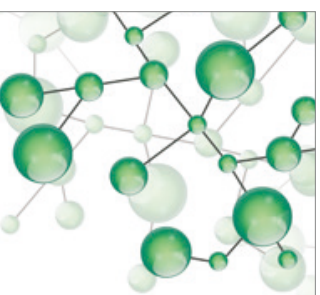

International Journal of

Inorganic Chemistry

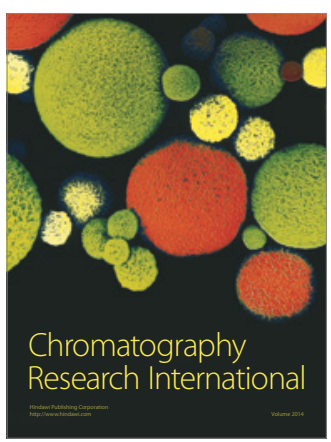

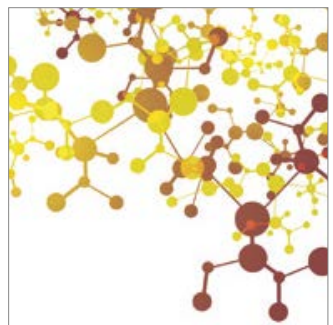

Applied Chemistry
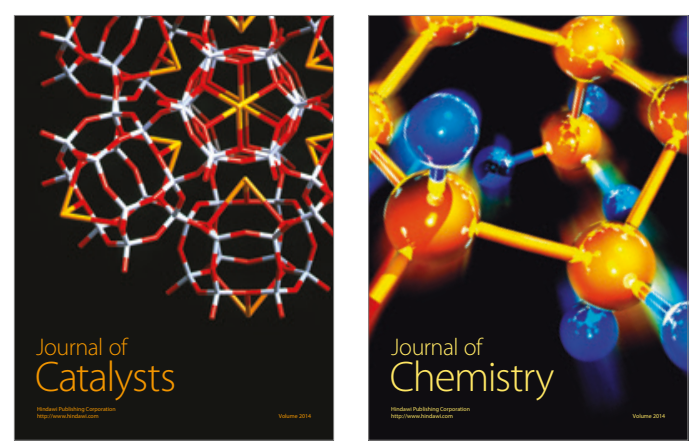
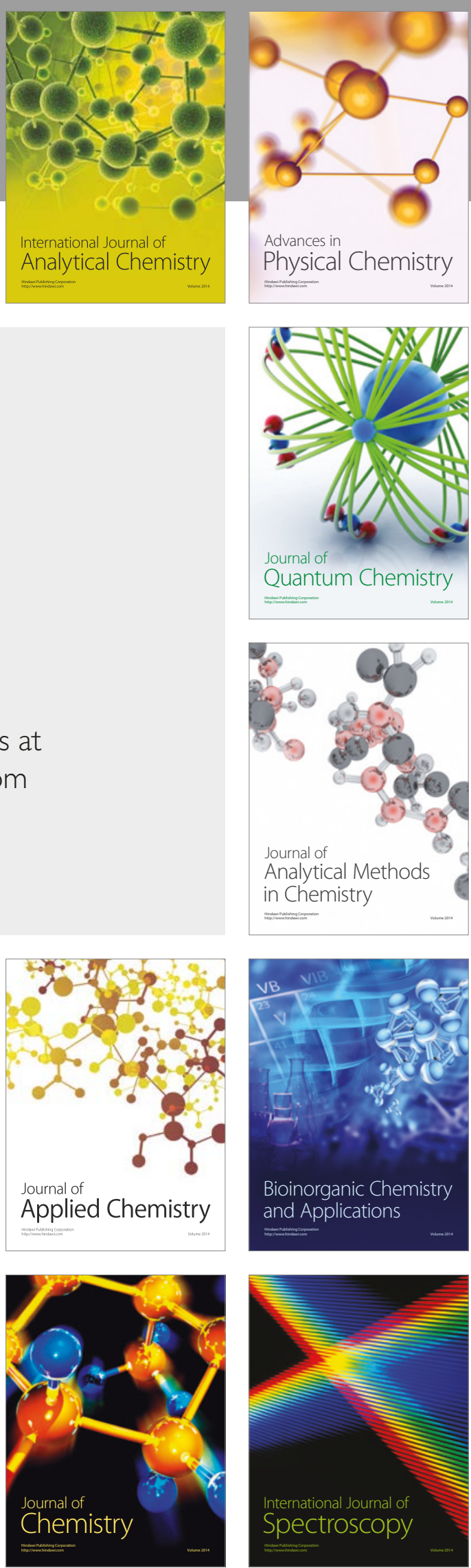